Tatiana Bubnova

Seminario de Poética, IIFL, UNAM

\title{
Delicado en Venecia, o de "corregidor" a "alcalde destas letras"
}

El 10 de febrero de 1528 Francisco Delicado, sacerdote español radicado en Roma desde hace un cuarto de siglo, abandona el alma cibdad con el ejército imperial, "por no esperar las crueldades vindicativas de naturales" (CA 508). ${ }^{1}$ Roma acaba de ser saqueada y maltratada brutalmente por la variopinta soldadesca de Carlos $\mathrm{V}$ durante diez meses (el Saco había iniciado el 6 de mayo del año anterior). Puesto que la ira de la tropa imperial, a cuya merced quedaba la población indefensa de Roma, estaba ideológicamente fomentada por el repudio hacia la conducta disoluta de la curia papal y, en general, la depravación de las costumbres del clero, la situación de Delicado en Roma era por demás ambigua. Siendo cura, se encontraba bajo peligro de una agresión por parte de las tropas presuntamente españolas -que en una considerable medida estaban constituidas por lansquenetes alemanes, muchos de ellos protestantes- 2 del emperador electo. El objeto de la ira de la soldades-

${ }^{1}$ Las citas del Retrato de la Lozana Andaluza provienen de la edición de Claude Allaigre (CA, seguido de número de página), Madrid, Cátedra, 1985.

2 “...sucedió en Roma que entraron y nos castigaron y atormentaron y saquearon catorze mil teutónicos bárbaros, siete mill spañoles sin armas, sin zapatos, con hambre y sed, ytalianos mill y quinientos, napolitanos rreamistas dos mill, todos infantes; ombres de armas seycientos, estandartes de ginetes treynta y cinco, y más gastadores, que cassi lo fueron todos..." (DA 437, 438). Los números oficiales 
ca eran preeminentemente las personas pertenecientes al estado eclesiástico, a pesar de que entre las víctimas había también muchos "civiles", por los cuales se pedía un rescate. Pero además de ser cura, Delicado era también español. En cuanto tal, pues, ¿qué le podía esperar en una Roma por fin abandonada por el ejército imperial, en el caso de que se quedara, sino las "crueldades vindicativas" de la población? Delicado sale de Roma juntamente con las tropas. Algunas de sus declaraciones ambivalentes que aparecen en los anexos de $L L A$, han dado pie para considerarlo un ferviente partidario del "castigo divino" infligido, por sus muchos pecados, al alma urbe, por el "brazo seglar" del emperador. ${ }^{3}$ No obstante, es de notar que Delicado no sigue al ejército de los "compatriotas" justicieros, que van hacia Nápoles, sino que emprende un itinerario diametralmente opuesto, y muy pronto se le ve en Venecia.

En la compleja correlación de fuerzas políticas en el escenario italiano, la ruta tomada por Delicado y la ruta que dejó de tomar resultan elocuentes: ir al sur con la tropa imperial significaba adherirse en cualquier forma a la política española del momento, o al menos, dejarse llevar por la corriente de los acontecimientos y las circunstancias personales. En cambio, ir al norte, especialmente a Venecia, significaba ir hacia una república italiana definitivamente hostil a dicha política (en palabras de Ana Vian, que resume la contingencia política en torno al Saco de Roma de 1527, "los venecianos son los más activos entre los hostiles a Carlos V"; Vian 18, nota 13).

En la ciudad adriática nadie esperaba a Delicado con los brazos abiertos: para todos era un total desconocido, que no halló, significativamente, "otro español en esta ínclita cibdá" (CA 508). Más aun: a pesar de haber obtenido en Roma, supuestamente, el vicariato de Valle de Cabezuela, en Extremadura, se-

acerca de los contingentes militares que entraron en Roma se aproximan bastante a los que da Delicado.

${ }^{3}$ Esto piensan, por ejemplo, Claude Allaigre y Louis Imperiale. 
gún consta en los finis de sus ediciones venecianas, y de haberle correspondido sus beneficios in curia (mera suposición, como la mayor parte de sus noticias biográficas), en el norte de Italia esto de nada le valió. Lo seguro es que en Venecia no ejerció su profesión, ni cobró beneficio alguno, sino que hubo de trabajar en una de las industrias más prometedoras, si bien novedosas, de aquel tiempo: la de las imprentas. Venecia era un centro editorial de importancia en toda Europa para la difusión de la letra impresa, y publicaba un espectro muy amplio de títulos, en diversos idiomas. En primer lugar, Delicado colocaría sus propias obras que trajo de Roma: el Retrato de la Lozana Andaluza, que dio a las prensas a pesar de ciertos escrúpulos —"por ser cosas ridiculosas" (CA 508)—, así como el tratadillo sobre la cura de la sífilis intitulado El modo de adoperare el leño de India Occidentale. ${ }^{4}$ En esta última obra, menciona haber conocido —deducción lógica, aunque no menciona su nombre- a Andrea Navagero, ex embajador de la Serenísima ante la corte de Carlos V, que acababa de regresar de una reciente embajada relacionada con la prisión de Francisco I después de la batalla de Pavía, y posteriormente con la Liga de Cognac.

Navagero siempre fue cercano a la industria de los libros, habiendo colaborado con el editor veneciano Aldo Manucio en la publicación de las obras latinas, ${ }^{5}$ de modo que no resulta inverosímil que el terreno del encuentro de ambos escritores fuese una imprenta, posiblemente la de Nicolini de Sabbio, o bien aquella librería de Juan Batista Pedrazano, en Rialto, la que tenía por insignia una torre, como consta en las ediciones venecianas de Delicado. Puesto que Navagero muere en Blois el 18 de mayo de 1529, para fechar el encuentro existe un mar-

4 Según Ugolini, ambas obras podrían haber salido a la luz en 1530. Para ver sus argumentos, Ugolini 1975: 485.

5 Cuidó las ediciones de Cicerón, Horacio, Ovidio, Virgilio. Asimismo, fue cronista de la ciudad y bibliotecario de San Marcos. 
gen muy estrecho: entre octubre de 1528 , cuando vuelve de su embajada en España y Francia, y mayo de $1529 .^{6}$ Justamente podemos visualizar a Delicado trabajando sobre las pruebas de sus obras, y la intervención de Navagero. Hablarían de Andalucía, de Martos, villa de donde era natural Delicado, y que Navagero visitó en 1526 , y de sus antigüedades romanas. A este encuentro seguramente le debemos la publicación, en el tratado sobre la cura de la sífilis escrito por Delicado, de unos epitafios romanos que Navagero transcribió en Martos. ${ }^{7}$ Las evocaciones de Martos interpoladas en La Lozana andaluza podrían también ser consecuencia indirecta de la intervención de Navagero. Del mismo podría provenir incluso la idea de publicar el Amadís y el del Libro segundo del emperador Palmerín... o, por más señas, el Primaleón.

${ }^{6}$ Delimitar la fecha del encuentro entre Delicado y Navagero puede ser importante para fechar la publicación de las propias obras de Delicado, relacionando los dados de los pies de imprenta de La LozanaAndaluza y de El modo de adoperare el legno... con el "calendario véneto" al que se refiere Ugolini.

${ }^{7}$ Las referencias a Martos y a los epitafios pueden encontrarse en el diario de viaje de Navagero. Quiero poner de relieve el curioso hecho de distorsión de la perspectiva histórica que deriva de la tradición, que aún no sé cuándo habría empezado, de fechar el "viaje", o más bien la embajada de Navagero a España en 1524-1526, como aparece en el título de varias ediciones contemporáneas de sus diarios de viaje (José María Alonso Gamo, Valencia, 1951; García Mercadal, 1950). La embajada duró hasta el otoño de 1528, cuando Navagero, habiendo pasado por Fuenterrabía, cruza por fin la frontera con Francia. Navagero se menciona por lo general en la historia literaria española en relación con su legendario encuentro con Boscán en los jardines del Generalife, y con la consiguiente reforma de la métrica castellana con arreglo a la italiana. Menéndez y Pelayo, en la Antología de los poetas líricos castellanos, pone acento sobre aquel encuentro y sus consecuencias literarias; no obstante, entra en todos los detalles políticos de la embajada de Navagero, y la describe hasta su última etapa, haciendo también referencia al período final de la vida del humanista veneciano. La tradición un tanto idílica del encuentro de Boscán con Navagero, de la que éste no da cuenta en sus diarios de viaje, contrasta con los acontecimientos mucho más tensos de la embajada posteriores a las noticias del Saco de Roma, algunos de ellos asimismo descritos por Menéndez y Pelayo. Me resulta importante destacar esta omisión (meramente visual, pues sólo se manifiesta en las portadas) de dos años de embajada, por la aparente impresión negativa que debió de haber llevado Navagero de su estancia en España. Poco después de terminar el "viaje", durante el cual le tocó estar, incluso, bajo arresto, Navagero tendría aquella supuesta conversación con Delicado 
Los libros de caballerías españoles empezaban a estar de moda en Italia, sobre todo en la situación de una creciente influencia política y cultural de España. En 1526, estando en Sevilla, Navagero envía, a través de su amigo veronés Juan Ramusio, ${ }^{8}$ un ejemplar del Primaleón para el magnífico Micer Gaspar Contarini (cf. también Menéndez y Pelayo 68). La literatura española despertaba interés: el marco de referencia político y cultural era el proyecto imperial de Carlos V, que irradiaba un prestigio de vencedor desde España y las conquistas españolas de ultramar hacia toda Europa. Delicado, además de sus propias obras, edita la Cárcel de amor (1531) y La Celesti$n a$ (1534). Los libros de caballerías, especialmente, eran la materia tal vez más vendible, así que le toca encargarse de la edición de dos de ellos: la del Amadís (1533) y la del Primaleón (1534).

Hacia 1533 Delicado se ocupa del Amadís, el libro más popular y prestigioso (se desconoce la edición que pudo haber seguido). Pudo haber sido la edición de Zaragoza 1508, o alguna que le sigue de cerca.

Básicamente, es corrector de las pruebas de imprenta. No obstante, su actividad no se limita a un trabajo tan mecánico, sino que el clérigo dos veces trasterrado incluye en la edición dos prólogos y varios finis y pies de imprenta, que son justamente aquellos que le habrán permitido a Gayangos, allá por 1857 , identificarlo como autor de la recientemente descubierta Lozana andaluza. ${ }^{9}$ Según su propio decir, introduce, además,

acerca de su patria. Para la interpretación, del todo especulativa, por lo ambiguo de las referencias textuales, de las actitudes políticas de Delicado, pongo juntos dos hechos: después de Roma, Delicado no sigue a las tropas españolas patrióticamente, sino que se dirige a un lugar hostil a la política del emperador; conversa en Venecia con un Navagero bastante fastidiado por las actitudes imperiales.

8 "Desde Sevilla informa Navagero a su amigo Ramusio sobre el envío, que le anuncia, de un ejemplar de la novela de caballerías el Primaleón, indicio de su búsqueda bibliográfica" (García Mercadal 837).

${ }^{9}$ El anónimo Retrato de la Loòana andaluza fue descubierto por Ferdinand Wolf en la Biblioteca Imperial de Viena en 1845. En la introducción al tercer libro 
unas correcciones sustanciosas y, se puede inferir, ciertos cambios estilísticos, algunos de los cuales se analizarán en este trabajo, en el Primaleón de 1534, empezando por el título mismo. ${ }^{10}$

Los prólogos que Delicado agregó a sus ediciones de los libros de caballerías, después de las transcripciones parciales de Gayangos en el siglo xIX y las de Eugenio Asensio en el xx (Gayangos xliv; Asensio passim), al parecer no se han editado como textos aparte, y no han sido analizados sino pocas veces. Aun así, han suscitado desde el principio varias reacciones entre negativas y despectivas por parte de la crítica. ${ }^{11}$ Así, Anna Maria Gallina dice que la actividad editorial del clérigo andaluz "si limitava a porre qualche prefazione anodina che non alterava in alcun modo l'originale" (Gallina 78). Eugenio Asensio es un crítico más severo: aunque no considera "anodi-

del Primaleón, Delicado dice: "cierto los que se apartan de la gramática española que es encerrada en aquella grande y famosa ystoria de Amadís de Gaula son sin duda nueuos romancistas, como lo fui yo quando compuse la loçana en el común hablar de la polida andaluzía".

${ }^{10}$ En realidad, se trata del "Libro segundo del emperador Palmerín en que se cuentan los grandes y hazañosos fechos de Primaleón y Polendus [ sic], sus fijos...", como aparece en la edición príncipe (ed. Marín Pina 3). Al final de la "Introvción del tercer libro" , Delicado explica: “...era Boz y fama que el Segundo libro de Palmerín estaua descoregido, yo con mi alma de cántaro riéndome de los que de mí burlaran partí el libro en tres partes y púsele el sobrenombre que él tenía por nombre propio, de guisa que como se dezía libro segundo de Palmerín, dixe: libro primero y segundo \& tercero de Primaleón". Así que el título con que este libro corrientemente se conoce se debe a Delicado.

11 Asensio considera que el primer crítico de la labor editorial de Delicado fue - Juan de Valdés, en el Diálogo de la lengua. Hacia 1535, cuando se escribe el Diálogo, Valdés se encontraba en Nápoles. Los soldados españoles cuyo representante en el Diálogo es el personaje Pacheco, se divertirían leyendo los libros de caballerías españoles editados por Delicado. La obra de Valdés contiene críticas del Vocabulario de Nebrija y de los libros de caballerías, en particular del Amadís, como bien se sabe. Puesto que Delicado se declara discípulo de Nebrija y se permite comentarios sobre los aspectos lingüísticos del Amadís, Valdés aparentemente dirige su crítica a Nebrija por mediación, por así decirlo, de Delicado. Ahora bien, el que Pacheco y sus congéneres tuvieran en sus manos necesariamente las ediciones de Delicado, no pasa de ser una mera hipótesis, aunque verosímil. M. Chevalier, en un reciente comentario sobre Juan de Valdés como crítico literario, no hace mención alguna de las ediciones de Delicado (Chevalier, passim). 
nas" las inserciones personalizadas de Delicado en las ediciones del Amadís y del Primaleón, las opiniones sobre la lengua española y las iniciativas, digamos, "hermenéuticas" del oscuro clérigo andaluz le parecen impertinentes y a veces hasta escandalosas.

En efecto, Delicado no sólo introduce en sus ediciones guías de pronunciación del español para italianos, ${ }^{12}$ sino que expresa opiniones varias sobre los textos de los que se ocupa, en sus diversos aspectos: sobre la excelencia de la lengua española (en el Amadís y el Primaleón), sobre el estatus jerárquico de sus dialectos (en el Primaleón), sobre la utilidad de la materia caballeresca para la educación del lector, sobre la correspondencia entre la realidad histórica y el contenido de las caballerías, sobre el arte de escribir, entre otras cosas más sutilmente matizadas. El tono entre irónico y festivo de sus ejercicios de prologuista, raya en una hilarante locura, que me parece sumamente fingida, a pesar de que la tomaran en serio los críticos del siglo $\mathrm{xx}$, sólo parangonable con las inspiraciones del famoso hidalgo de La Mancha, el lector tal vez más asiduo del Amadís, Primaleón y de toda su descendencia. La malicia que los prólogos transpiran parece estar emparentada con la desatada "malicia malencónica"13 de los anexos del Retrato de la Lozana Andaluza.

De entrada, hay juegos lingüísticos. En el primer texto suyo inserto en el Amadís se declara "corigidor" del libro. El traslape al principio puede parecer del todo inocente: "corregidor" y "corrector" son semánticamente tan cercanos que se puede suponer lícito un uso no del todo exacto, pero comprensible, del vocablo. Ahora bien, Delicado sabía usar perfectamente la se-

12 Justamente ponderadas por Amado Alonso en De la pronunciación medieval a la moderna en español, $2^{2}$ ed., Madrid, Gredos, 1967, t. I.

${ }^{13}$ Cf. T. Bubnova, "La malicia malencónica de Francisco Delicado", en Estado actual de los estudios sobre el Siglo de Oro, Salamanca, Editorial Universidad, 1992, pp. 195-202. 
gunda palabra, porque en varios finis se declara como "corretor": así, en el prólogo al tercer libro del Amadís aparece ya como "corretor de la impressión". 14

Escribe en el Prohemio del "corigidor de las letras mal endereçadas":

En glorioso siglo cuando el muy sabido Autor del presente Libro dexó en memoria no solamente la vida, forteça, gloria, esfuerço \& fechos animosos, mas la cortesía, gentileza \& limpieza de vida muy acostumbrada, la passión del amoroso amor, el orgullo de real cauallero, el coraçón no uençido, la gloriosa memoria de la fama, la lealtad tan alta y tan leal, la verdadera y justa justicia, acompañada de razón \& verdad; la compassión con piedad acompañada, assí de amigos como de contrarios, usando con todos gracioso agradecimiento, como a loçano \& de buenas maneras cauallero le conviene. Esto todo nos mostró en esta tan sabrosa obra el sabido conponedor, mostrando en Amadís de Gaula todas aquellas virtudes que cada hombre Bueno: ${ }^{15}$ \& Caualleros, Duques, Condes, Marqueses, Señores, Reyes y Emperadores han de tener, seguir y mantener.

La aparentemente casual ruptura del campo semántico de la nobleza por la imupción del eslabón del tercer estado - "hombre bueno"- la comentaré más adelante en relación con otros elementos más. Dechado moral para la nobleza (nótese la significación específica que Delicado atribuye al término 'hombre bueno', al colocarlo en una misma serie con la nobleza),

[e]ste libro se celebra por muy antiquíssimo \& assí lo parece en el su gentil y gracioso estilo. En esta obra está el arte para

14 Covarrubias resume tanto el parentesco como la bifurcación semántica de los dos vocablos en un párrafo muy sucinto, $s$. $v$. 'corregir': "Vale emendar; de donde se dijo corrección. Corretor en las religiones. Corretor de libros, el que corrige las erratas de la impresión. Corregir, castigar. Corregirse, emendarse. Corregidor, el que rige y govierna alguna ciudad o pueblo, latine praetor" (énfasis mío).

${ }^{15}$ Leo asi la abreviatura hombre $B$ - que aparece en el original, de acuerdo con Capelli, s.v. B. 
mostrar a ser los caualleros espertos y animosos \& para los fazer mesurados \& corteses. Assí mesmo está el arte de los verdaderos enamorados, la religión de las armas, a quien notarla quisiere. El modo assí mesmo de la moderación de las justicias. Y el exemplo de jamás la fe dada \& palabras prometidas quebrantar. Haziendo \& dando derecho a quien con verdad y razón se lo demanda. Defendiendo las Dueñas y donzellas, honrrándolas y serviéndolas, amándolas según sus merecimientos, poniendo por ellas las fuerças a muchos peligros. $\mathrm{Y}$ esto alça y endereça nel glorioso arte de la Milicia: cual es de grande osseruança. No el presente mas el passado, digo.

El "glorioso arte de la milicia", de acuerdo con esta apreciación, lo fue en un pasado que nada tiene que ver con el presente. En el contexto de las guerras españolas en Italia, con la reciente experiencia del Saco de Roma del 1527, permite ver en la discreta observación de Delicado un definido contraste entre el universo poético de los libros de caballerías y la realidad cruda de las guerras contemporáneas que nos hace recordar una vez más a Cervantes.

Luego, en el mismo Amadís agrega algún matiz que llamaríamos, quizás ilegítimamente, teórico-literario, que cualquier lector atento de La Lozana andaluza reconoce como familiar: ${ }^{16}$

Quán maravillosamente este Autor uos pintó este cauallero Amadís de Gaula? Y hízolo por fazer la razón: que los Pintores \& Poetas y estoriadores como él, tienen licencia de Pin-

- tar y dezir lo que a ellos mejor les pareciere, para fazer sus obras en todo \& a todos hermosas.

${ }^{16}$ Los tópicos de pintores, poetas e historiadores se encuentran en el trasfondo del Argumento antepuesto al Retrato de la Lozana andaluza, y su significación aparece activada justamente mediante la idea de retrato ("sacado del natural"). La Lozana comienza como "historia o retrato sacado de jure cevil natural" (CA 175), con una tremenda ambivalencia semántica. En este sentido, se opondría al Amadís en términos de concepción teórica, al proclamar el propósito estético del Amadis un tanto artistotélicamente. 
Ahora bien, en la Lozana andaluza Delicado se atiene -en teoría - al supuesto realismo de la noción de 'retrato' ("solamente diré lo que oí y vi"), con un matiz además moralizante y reprensivo, aunque también ambivalente, si hemos de creerle a Claude Allaigre, ${ }^{17} \mathrm{e}$ invita además al lector a quitar y poner al Retrato según su propio criterio, ${ }^{18}$ en aras de serle fiel al "natural". La discusión de la crítica reciente (fundada en la semiótica y teoría literaria) en torno al dudoso realismo del Retrato, en contraste con las primeras generaciones de los filólogos que estuvieron de acuerdo acerca de la actitud realista, incluso "fotográfica", de Delicado, hace recargar la balanza interpretativa hacia el doble sentido y el moralismo a la vez. En torno a la cuestión del realismo siempre ha habido muchos malentendidos. El doble sentido y la caricatura no cancelan el referente, que es, en el caso del Retrato, una sociedad muy concreta con sus vicios y abusos, por más simbólicos que sean los personajes. El realismo es menos efecto que actitud hacia la materia representable. En cualquier caso, todos hemos de acordar en que al menos en relación con el tratamiento que se da al lenguaje, que incluye tanto la concepción - la "verdad" de la lengua materna y la de la calle-, como la actitud (contrastar lo libresco y lo cotidiano en cuanto al lenguaje) sí es, definitivamente, de intención "realista", en cuanto orientación hacia lo existente y no hacia lo especialmente creado. ${ }^{19}$

La diferencia se pone de manifiesto justamente en relación con las opiniones literarias que Delicado expresa en sus prólogos venecianos. En el Prohemio del Amadís, el matiz idealizan-

17 Cf. la Introducción a CA 85, pp. 45-79.

${ }^{18} \mathrm{~S} \epsilon$ trata, por lo demás, de un tópico medieval integrado hábilmente a los propósitos del autor.

19 “Y si quisieren reprehender que por qué no van munchas palabras en perfeta lengua castellana, digo que, siendo andaluz y no letrado, y escribiendo para darme solacio y pasar mi fortuna, que en este tiempo el Señor me había dado, conformaba mi hablar al sonido de mis orejas, qu'es la lengua materna y su común hablar entre mujeres" (CA 484-485; énfasis mío). 
te que le atribuye al texto de Montalvo es patente, complementado con un deseo de contrastar las realidades librescas con la actualidad. Es un aspecto que más adelante se va a relacionar con el cambio de actitud ante la lengua que se observa en los textos de Delicado, en lo que va de La Lozana andaluza a los prólogos venecianos.

El carácter fabuloso e idealizante del Amadís puede ponerse en relación con la percepción que Delicado tiene de su lengua, "como abajo veremos". Quisiera subrayar una vez más que a lo que debemos prestar atención es a lo que la materia que reseña significa para Delicado, no lo que es para Valdés o para la crítica de la segunda mitad del siglo xx.

Su talante de crítico y hasta de teórico literario, que se pone de manifiesto en la descripción de las "tres fortunas" de Amadís, le permite condensar temáticamente la narración del nacimiento, la salvación milagrosa, y la fortuna en la caballería y la suerte en el amor, o sea, "agua, armas y amor", ${ }^{20}$ de hecho sigue desplegándose en términos folklórico-comparatistas avant la lettre, aunque sus referencias, como es de esperarse, sean bíblicas y hagiográficas:

Diole a este cauallero Amadís de Gaula fortunas muy apropiadas. La primera, echado en el arca cerrada por las aguas del mar, y en esto se assemejó a aquel gran Profeta Moysés y como cuenta el libro que ha nombre Gesta Romanorum, de san Gregorio que fue por el semejante lançado en el mar, de su madre y su hermana. ${ }^{21}$

En cuanto al amor, un lector atento tiene el privilegio de reconocer otra vez la actitud tan abierta de Delicado ante el ero-

20 "Cierto: se puede creer que auiendo fe se le mostraba la fortuna en estas tres visiones de Agua, de Armas y de Amor. Vido y una adoró. Amó, sirvió \& siguió, como verdadero Amador dicho Santo Amador Amadís. En todo cabo de bienaventurado nos lo dio esculpido".

${ }^{21}$ No olvidemos del cronotopo del nacimiento de los personajes, concepto al que Delicado es tan sensible como cualquier crítico del siglo veinte que contrasta 
tismo, expresada con anterioridad en la misma Lozana andaluza: ${ }^{22}$

La tercera fortuna fue la fe del amor, el qual siguió con acabada esperança en el su criador $\&$ señor al qual amaba sin fin con el espíritu; y el gracioso amor corporal a que la maestra natura lo inclinaba acabando tan affortunadamente, como su firmeòa lo acabó.

Por más lascivo que los amores del Amadís y del Primaleón les parecieran a Valdés y a otros humanistas, no pueden ni remotamente compararse con aquellos que administra Lozana en Roma. Los amores literarios sirven de parodia y de material para doble sentido a los personajes del Retrato, cuya procacidad, aunque fabulosamente inflada, no tenía nada de irreal, sino que andaba por las calles en forma del lenguaje erótico callejero cuya preservación le debemos justamente al clérigo andaluz.

Luego Delicado dice que destina su edición no sólo a los españoles, sino a todos aquellos que quieren poder leer español: "los Latinos, Ytalianos diversos, toscanos, tudescos, Franceses, Ingleses, Úngaros \& Portogueses. Y finalmente todos aquellos a quien plaze el romance Castellano por ser tan pelegrina lengua".

Y certíssimamente este libro es el verdadero arte de la Gramática Española, porque en sí encierra Reteloquendi \& Requete

el nacimiento en el río Tormes de Lazarillo y el fabuloso del Doncel del Mar: Lozana nace en Córdoba, como su autor, y después está en Roma, entre el último tercio del siglo xv y el primero del xv. Ahora bien, tanto el Amadís como el Retrato describen hechos imaginarios, aunque concebidos desde distinta cronotopia: imaginemos un Doncel del Mar desfilando por la calle de los Bancos, o por el callejín Calabraga (hoy calle Benvenuto Cellini). Efecto quijotesco, una vez más.

22 "Y como la mujer sea jardín del hombre, y no hay cosa en este mundo que tanto realegre al hombre esterior, y que tanto y tan presto porque no solamente el ánima del hombre se alegra en ver y conversar mujer, mas todos sus sentidos, pulsos y miembros se revivifican incontinente" (CA 484). 
escribendi. ${ }^{23}$ Assí que a todos ruego se contenten assí como lo hallaren que assí lo hallé yo: avisándos a todos que a falta de Omes Buenos me fizieron alcalde destas letras.

Ahí está el punto que fue motivo de la indignación de Asensio, porque según él, el Pacheco valdesiano (la soldadesca española en Nápoles) y Delicado cometían el mismo error histórico en la apreciación del lenguaje del Amadís, anticuado y afectado. ${ }^{24}$ Arte, y no el "natural" lozanesco,"es lo que Delicado subraya en el estilo del Amadís.

El paradigma de los personajes caballerescos del Amadís está trazado desde el principio del citado Prohemio: "cada hombre Bueno, \& Caualleros, Duques, Condes, Marqueses, Señores, Reyes y Emperadores". En la introducción al libro cuarto del Amadís, se reitera: "Assí que quanto los caualleros y hombres buenos, Condes, Duques y Marqueses, reyes, Soldanes y Emperadores deuen ser obligados a las mugeres". Delicado define su propio puesto social en relación con un contenido tan excesivamente "nobiliario" del libro sobre el que ejerce su poder de "corregidor", elevado en una dignidad aun mayor: "a falta de omes buenos me fizieron alcalde destas letras". En el anexo de la $\mathrm{Lo}$ zana andaluza intitulado "Como se escusa el autor..." Delicado se declara de la siguiente manera: "mi oficio me hizo noble,

23 Juego lingüístico, típico de Delicado, de construir palabras híbridas, aquí a base del gerundio latino y preposiciones españolas vulgares, a más de transformar un lexema de lengua vulgar en un latinajo cómico aplicándole la morfología del latín: un proceder macarrónico, digno de los ejercicios de Merlín Cocaio (cf. infra). Cf.' en latín: recte escriuendi speties.

${ }^{24}$ Aquí podemos aventurar una analogía un tanto ilegítima, por parangonar a los personajes históricos con los literarios: el Pacheco de Valdés es representante de aquella tropa imperial en Nápoles a la que Delicado no quiso acompañar, dirigiéndose a una Venecia hostil a la política imperial. No olvidemos que los hermanos Valdés (Juan y Alfonso) son los propagandistas de la política de Carlos $\mathrm{V}$ en Italia. Alfonso de Valdés, como sabemos, es autor de dos diálogos dedicados especialmente a justificar en términos políticos y hasta teológicos el Saco de Roma. Según nuestra crítica actual, Delicado estaría de acuerdo con los doctos hermanos Valdés; ahora bien, Delicado está en Venecia, mientras Juan de Valdés en Nápoles: una perfecta articulación histórica de posiciones políticas mediante la cronotopía. 
siendo de los mínimos de mis conterráneos" (CA 485), lo cual quiere decir que era plebeyo ennoblecido por el oficio de sacerdote. "Buenos hombres" es, según él, una categoría equiparable a la nobleza, ${ }^{25}$ cuyo estatus Delicado no alcanza para ser elevado de "corregidor" a "alcalde" de las letras que gobierna. Más adelante veremos que seguirá coherente con su nuevo "cargo" de alcalde en su trabajo sobre el Primaleón.

Es verdad que tanto en el Amadís como en el Primaleón el "alcalde" lego ${ }^{26}$ de las letras caballerescas promueve el valor educacional de las caballerías, viendo en sus personajes un ideal heroico al que habría de aspirar el lector contemporáneo. Pero bien mirado, este ideal se vuelve más igualitario que exclusivista y aristocrático, gracias a las ambivalencias y aun la "incongruencia" misma (apreciación de Asensio) de poner en una misma serie aquello que debía permanecer jerárquicamente separado. El principio democrático inaugurado en los prólogos del Amadís, en los cuales el libro se convierte en el ejemplo a seguir tanto por el tercer estado como por los reyes, y los grandes, y los nobles, penetra subrepticiamente en la introducción al primer libro del Primaleón, en el cual el arte de caballería no es ya exclusivo de la nobleza, sino que aparece como una manifestación universal, transhistórica, e hilarantemente dudosa. Porque

quando començó el glorioso arte de la Cauallería en Adán con una Açada y en Cayn con un cuchillo, y en su nieto con un Arco, y en Dauid con una piedra en una honda, y en Gesué con maças, y en Iudas Machabeo con un trabuco, y en Iudic [sic] con un cuchillo, y en las amazonas armadas de broqueles

${ }^{25}$ Aunque el Diccionario de la Real Academica Española defina esa categoría como perteneciente a estado llano, siguiendo al de Autoridades, que $s$. $v$. 'Hombres buenos' los define como de "humilde y baxo linage", el Tesoro de Covarrubias no posee referencias directas a la expresión en cuanto término "sociológico"; no obstante, su pertenencia al tercer estado es indudable.

${ }^{26}$ En $L L A$ se declara "iñorante" y "no bachiller", a pesar de que en uno de los prólogos aquí reseñados dice que Antonio de Nebrija ("Librija") fue su preceptor. 
\& de los Sirios con alfanges, san Pedro con gañivete \& Santiago con la espada, y Longino con una lança, y san Jorge con una azagaya [...] con otros caualleros de alta bondad, assí antiguos como modernos, que alçaron el arte de la cauallería, que serían muchos de contar.

Y en efecto, el "corregidor y alcalde de las letras" sigue poniendo muchos ejemplos históricos, mitológicos y literarios, de dechados de caballería sacados de diversas épocas, países y fuentes. Mujeres y hombres, "helenos o judíos", "Griegos barbudos" y "triunfantes Romanos", "ellos y ellas", tirios y troyanos, egipcios y asirios, italianos y españoles contemporáneos, todos han ejercido, desde siempre, "el gloriosso arte de la cauallería". Lo cual, no podemos negarlo, hace desmerecer su exclusividad nobiliaria. Mientras tanto, como hemos visto, en los tiempos contemporáneos las guerras han perdido ya ese carácter caballeresco que los libros de caballerías exhiben. Definitivamente, Delicado parece prever que la imprenta a la larga iba a democratizar la lectura.

Pero especialmente interesante es que la familia de los Fernández de Córdoba, nobles andaluces, sean directamente los héroes de la novela. Es otro punto que disgusta a Asensio, quien tomó en serio las declaraciones hilarantes del clérigo andaluz. Hemos de preguntar de dónde vienen estas referencias a una familia concreta de Andalucía en la referencia a las hazañas de los fabulosos cabelleros andantes. Resulta que el conde de Cabra, señor de Baena, don Diego Fernández de Córdoba es el mismo Primaleón, y su pariente don Gonçalo Fernández de Córdoba es ni más ni menos don Duardos. Lo que sucede es que Delicado retoma elementos previamente existentes en las ediciones del Primaleón y los integra en su propio metatexto.

En la edición del Primaleón de Sevilla, 1512 (editada recientemente por María Carmen Marín Pina), aparece la dedicatoria a don Luis Fernández de Cordoba. Sin buscar explicaciones de este hecho que serían por el momento demasiado 
especulativas, destacaré tan sólo que Delicado pone en coherencia la dedicatoria original mediante la mención de los otros miembros de la mencionada familia de los nobles andaluces. Es en esta dedicatoria donde se insinúa una relación entre los personajes del libro y la familia Fernández de Córdoba, como si la fabulación novelesca, que finge ser una "historia greciana", ${ }^{27}$ tuviese algún paralelo en los hechos y personajes históricos. ${ }^{28}$ Aprovechando este antecedente, en uno de los tres prólogos al Primaleón Delicado va más allá de una simple referencia al expropiar de la dedicatoria al personaje sin duda histórico, e incorporarlo a la interpretación de los personajes fabulosos del Primaleón. De este modo, el resultado es el de hacer que la dedicatoria pase a formar parte del texto del libro, mediante esta interpretación. No obstante, la subversión de las genealogías nobiliarias que menciono aquí ("Adán con la azada", etc.) crea un delicioso contrapunto entre esta especie de "Nobleza del Andaluzía" 29 que es la dedicatoria, y la figura de un san Pedro "con gañivete" (palabra que Valdés reprueba) haciendo de antepasado de los caballeros andantes.

En realidad, las respectivas dedicatorias del Primaleón de 1512 y la de 1534 no son idénticas, pero en este momento no

27 "El tiempo y el espacio de la obra quieren ajustarse en principio a la convención de presentarla supuesta crónica griega, como la historia de Palmerín y Primaleón descendientes de Constantino, y por ello cobra especial relieve la geografía griega (Constantinopla, Delfos, Lacedemonia, Macedonia) que acaba por desplazar definitivamente la artúrica" (Marín Pina XII).

${ }^{28}$ En realidad, no pasa de ser una figura del paralelismo, una leve insinuación, al decir. "Veis aquí, magnifico señor, como todos sois castizos y como en vuestro linaje todos acuden al tronco [porque se acaba de describir toda la genealogía de los Córdoba - TB]. E es por esto, no es de maravillar si a Palmerín, que los días passados publiqué y saqué a la luz en vuestro nombre, sucedio Primaleón, heredero y sucessor no solamente de la casa y estado, mas aun de las hazañas estremadas en la professión de la cavallería. No porque de allí Vuestra Señoría pueda deprender cosa alguna, salvo reconocer los hechos de sus mayores, mas porque de su favor se siga autoridad a esta mi obra según se hizo en la pasada" (Marín Pina 2).

29 Título del libro genealogico y heráldico de Gonzalo Argote de Molina, publicado en Sevilla ("por Fernando Días, Año 1588"). 
puedo establecer si las diferencias introducidas se deban a Delicado o si las copió de la edición intermedia de Toledo 1528 que supuestamente fue la que le sirvió de modelo y la que corrigió. En la primera parte del texto se pueden detectar lecturas levemente distintas, que pueden considerarse como imprecisiones o descuidos de lectura, mientras que en la parte final existen inserciones más importantes, si bien mínimas, que pueden interpretarse como ampliación adulatoria. Por ejemplo, si en la de Salamanca dice: "Veis aquí, magnífico señor, como todos sois castizos y como en vuestro linaje todos acuden al tronco", en la de Delicado leemos: "Veys aquí magnífico señor como todos soys castizos Leones \& como en vuestro linage todos acuden al tronco como si dixesemos que fueron vuestros antecessores primero Leones". El titular de la dedicatoria es don Luis Fernández de Córdoba (desde la edición de Salamanca 1512), pero en la de Delicado aparece una precisión: "que fue después Ylustríssimo Duque de Sessa y Cessareo Embaxador Rome [sic]".

Ya mencioné que Delicado introduce toda una serie de cambios en el formato del libro que desde su intervención se llamaría Primaleón, cambios que hacen su edición bastante distinta de las demás ediciones españolas. Al dividir el libro en tres partes altera la capitulación corrida de las ediciones anteriores y de las posteriores que las reproducen. En un cotejo superficial entre Salamanca 1512 y Venecia 1534 , se detectan tanto las coincidencias, sobre todo en el uso de algunos vocablos anticuados (como todas las incidencias de 'ledo'), que en las ediciones de Medina 1563, Lisboa 1566 y 1598 aparecen sustituidas por 'alegre', o "Apoloña" por "Polonia" como las alteraciones, algo más sustanciosas. Un ejemplo. Al final del capítulo cvxiii de Salamanca 1512 (y en las posteriores que acabo de mencionar), ${ }^{30}$ dice: "Ansí lo fazed, señora, dixo la infanta. $\dot{E}$ sabed que Gridonia era tan leda que no hay quien vos lo pudiesse dezir porque el Cavallero de la Roca Partida fazía 
tanto por ella, que todos gelo tendrían a gran mal si ella no le diesse el galardón, y éste avía de ser ella misma". Delicado es un poco más gráfico: "Assí lo fazed, señora, dixo la infanta. $\&$ sabed que Gridonia era tan leda que no ay quien vos lo pudiesse dezir porque el cavallero de la Roca Partida fazía tanto por ella que todo gelo tendrién a gran mal: si ella no le diesse el galardón, juntamente con su propia persona. Pues assí lo mereçía".

Otro ejemplo es el episodio de la seducción de Flérida por Julián (o don Duardos). Esta escena aparece casi idéntica en la edición de 1512 y en las de Medina y Lisboa. En la primera, dice así: "Y como vido que era tiempo, púsolo por obra y, con grandes falagos y amor demasiado que le mostró y más por fuerça, la fizo dueña. Y aviendo alcançado tan gran cosa, él quedó tan ledo que no hay hombre que vos pudíe dezir y la infanta muy sañuda..." En cambio, en Delicado encontramos: "Y como vido que era tiempo púsolo por obra: y con grandes falagos y amor demasiado que le mostró, y algo por fuerça, porque la gritadora no osó dar bozes, la fizo dueña. $Y$ aviendo alcançado tan alto fin, él quedó ledo, y la infanta muy sañuda..."

Estos ejemplos, que ya salen propiamente del marco de los prólogos de Delicado, los menciono aquí como una constancia del tipo de trabajo realizado por el clérigo andaluz, según él mismo declara, sobre la edición que le sirviera de modelo: la de Toledo 1528, que con todos los reproches que el "corregidor" le dirige, ${ }^{31}$ debió haber sido bastante cercana a la príncipe.

${ }^{30}$ Claro, en la de Medina del Campo y en las dos de Lisboa 'ledo' aparece cambiado por 'alegre', gelo por selo, 'fazed' por 'haced', entre otras modernizaciones semejantes, pero el texto mismo es idéntico al de Salamanca. No así el de Delicado.

31 Dice Delicado sobre el Primaleón toledano: "No es de maravillar si los leyentes ya no lo querían ver ni oyr en ninguna manera a este livro, porque os juro cierto que en todo él no hallé renglón ni razón que concertada estuviese, no palabra que derechamente fuesse verdadera en romance castellano. Digos que eran las letras tan trastocadas, que havía el libro lo de dentro fuera, que parescié frisado". Y 
$\mathrm{Al}$ reforzar unos rasgos y mitigar otros, Delicado consigue un resultado un poco más enfático desde el punto de vista estilístico justamente en lo tocante a los detalles eróticos que son su "marca de fábrica".

Creo que en los ejemplos que aduje queda suficientemente demostrada la actitud de "alcalde" que Delicado ejerce sobre el texto.

Ahora bien, eso de "alcalde", en cuanto ascenso de "corregidor", tiene sus bemoles o, más bien, ambivalencias (mal)intencionadas para con el lector, que debe de alguna manera entender los motivos de esta transformación. Para empezar, incluso históricamente, el rango de corregidor bien podía ser superior al de alcalde: depende del caso. En la práctica, los alcaldes de pequeñas villas bien podían pertenecer al tercer estado: el "alcalde de Zalamea", los "alcaldes de Daganzo" (el primero, de Lope y Calderón, podía tener gran dignidad literaria, incluso en comparación con la nobleza, mientras que los segundos - los de Cervantes - han quedado como prototipos de estupidez y simpleza.

Delicado, en efecto, sobrepasa con creces las funciones de "corregidor" de las letras que le fue asignada en la edición del Primaleón y, asumiendo las de "alcalde", da de veras, como él dice, varias "alcaldadas", al afirmar toda una serie de opiniones, que hasta ahora pueden parecer estrambóticas, sobre la lengua y la literatura, sobre el dudoso papel educativo de los libros de caballerías (cuestionado por Juan de Valdés, por santa Teresa, entre otros), anticipando al mismo tiempo la ambivalencia cervantina con respecto a eso de tomar en serio la materia caballeresca. La alcaldada, que en su acepción más inocente podría significar "accción de alcalde", en realidad nos remite a una necia arbitrariedad de gente ignorante. El círculo se cierra:

todo ello porque, según el cura andaluz, ni el editor Cristóbal Francés, ni los impresores Cosme y Damián habrían nacido en Zocodover (una manera irónica de decir que eran extranjeros). 
el discurso de Delicado, autoprovocativo y cuestionador de sí mismo, ambivalente y jocoso, cuyas bases habían sido asentadas en La Lozana andaluza, se estructura con características similares en los prólogos a los libros de caballerías. Sin embargo, su actitud hacia la lengua parece haber cambiado, o adaptado a una nueva situación.

Delicado escribe en Italia. A pesar de no haber tenido, por varias razones, un público amplio para su Lozana andaluza, sino más bien uno confinado a ambientes más reducidos de compatriotas y amigos capaces de entender el español, el libro en cierta forma transpira la conciencia del plurilingüismo de la "plaza pública" romana en cuyo medio se sitúa el autor en el momento de escribirlo. En cuanto escritor que ambienta su creación en Italia, su "retrato" se inscribe, en el momento en que aparece, en el conjunto de las obras que se apartan de la tendencia, que se está introduciendo en este período por Bembo, de fundar una lengua, un italiano culto común con base en un toscano refinado y arcaizante, alejado del habla florentina real que prevalece en la época. ${ }^{32}$ Las tendencias plurilingües y macarrónicas presentes en La Lozana andaluza, como ha sido notado por Antonia Fucelli, permiten inscribir al clérigo andaluz, en cuanto escritor "italiano" - y lo digo con todas las reservas posibles que vengan al caso-, en el conjunto de los escritores "irregulares", tales como Folengo o el Ruzzante, que se orientan, con plena conciencia, al habla dialectal y sociolectal como recurso con gran potencial de caracterización (cf. Petronio 1978, 30-39), que permite descubrir, en el habla que usa un personaje, toda una visión del mundo. Ahora bien,

32 Significativamente, en España sucede un proceso paralelo, cuyo indicador es la empresa centralizadora (de la lengua) de Juan de Valdés. Sin equiparar su esfuerzo con el de Bembo, es pertinente señalar el paralelo en cuanto tendencia hacia la fundación de una lengua nacional. Por otra parte, la "lengua compañera del imperio" anunciada ya por Nebrija, cuyos avances, según Eugenio Asensio, Juan de Valdés rechazaba, cuaja como un primer intento precisamente en el Diálogo de la lengua. 
¿cómo cambia esta actitud lingüística de Delicado en los prólogos venecianos?

Ciertamente, las opiniones y actitudes de Delicado en torno a la lengua española no pueden considerarse homogéneas e invariables en el paso de La Lozana andaluza a los prólogos venecianos. En La Lozana andaluza, que es un "retrato", el autor confiesa que "conformaba su hablar al sonido de sus orejas, qu'es la lengua materna y su común hablar entre mujeres" (CA 485). Y admite que siendo andaluz y no letrado, no habla en la perfecta lengua castellana. La calidad "oral" de las hablas que Delicado reproduce en esta obra ha sido suficientemente destacada por la crítica. En el Amadís, en cambio, ve Delicado el ejemplo prestigioso de lengua literaria, si bien no lo retoma acríticamente ${ }^{33}$ en cuanto su procedencia dialectal. El habla toledana en este momento está alcanzando el rango de la modalidad principal culta para un español común. No obstante, el principio horizontal (geográfico) de la centralización lingüístico-ideológica no es suficiente: muchos vocablos del habla toledana, infestada con un exceso de arabismos, son "zafios"; las formas verbales en uso son anticuadas y no resisten la prueba del tiempo. Mientras que el habla de la corte toledana sí puede servir de modelo para un español general: el principio vertical completa la idea de la centralización lingüístico-ideológica en torno al castellano de la corte.

${ }^{33}$ En la Introdvción del tercer libro dice lo siguiente: "Que cierto que los que se apartan de la gramática española que es encerrada en aquella grande y famosa ystoria de Amadís de Gaula son sin duda nueuos romancistas, como lo fui yo quando compuse la loçana en el común hablar de la polida andaluzía. Mas fízelo por mejor arrendar en la manera de su hablar, assí que yo mismo por poder deprender aquella suavidá \& razonamientos y aquellos fermosos uocablos y machuchas palabras toledanas que en Amadís están lo tomé a corregir; no digo a corregir el libro, que cierto si él fuera Libro de la sagrada escritura yo no tuuiera tanto miedo de quitar ni a juntar, porque él no lo hauía menester, que está bien. Mas como uos digo con zelo que los of ficiales de las letras no trastocassen y cohondiesen tan exçelente obra, y también [sic por 'tan bien'] ordenada como es ella, porque allí deprendí yo para ser bachiller deste otro libro de Primaleón, digo que deprendí la Orthografía de Castilla la alta, porque soy de Castilla la baxa..." 
Las opiniones lingüísticas de Delicado se encuentran concentradas en la introducción del "tercero libro" del Primaleón. No obstante, ya en el prohemio del Amadís, como hemos visto, se considera el texto de Montalvo como dechado de la gramática castellana (su "Reteloquendi \& Reteque escriuendi"), por ser ejemplo del toledano, ${ }^{34}$ opinión que repite en el prólogo al libro mencionado del Primaleón. En ese comentario al Primaleón, Delicado subraya que sólo el habla cortesana de Toledo puede servir de modelo del buen decir en español, porque a pesar de que, supuestamente, el haber nacido en Zocodover ${ }^{35}$ es una especie de garantía de la corrección lingüística, los rústicos toledanos usan muchos vocablos y formas anticuadas y desprestigiadas, además de los abundantes arabismos, como para servir de modelo de lengua culta y literaria. Aun así, "se deue escuchar el hablar de un rudo Toledano en su çafio razonar que no al Gallego letrado y al polido Cordoués". Esto es muy distinto de lo que aparece en La Lozana andaluza. No obstante, de acuerdo con la "alcaldada" que da el "corregidor" de las letras caballerescas, el habla de Andalucía sí se salva en cierta medida como afín a la de Castilla la Nueva.

El terreno para una aproximación a este aspecto ha sido ya suficientemente desbrozado por Eugenio Asensio, cuya fina visión analítica es indiscutible. Otra cosa es la intrasigencia ideológica, que lo hace rechazar todo lo andaluz sólo por serlo. Delicado distingue entre Castilla la baja (Andalucía, que son "de Toledo acá yuso"), y Castilla la alta (el Reino de Toledo).

34 Ahora bien, sólo nos queda hacer conjeturas acerca del por qué el regidor de Medina del Campo compusiera, en opinión de Delicado, una obra de acuerdo con los criterios del habla toledana. Ningún comentarista hasta ahora, que yo sepa, ha llamado la atención hacia esta pequeña inconsecuencia, que puede implicar la edición prototipo que Delicado usara para ordenar su edición del Amadís. Recuérdese que para el Primaleón si se basó en una edición toledana.

35 "No guardan la honra del que lo compuso puniendo estrangeros aljamiados a lo coregir". Y, peor aun, "puniendo uocablos que no los hallaron en todo el reyno de Toledo aunque uiniesen los cazadores del Rey don Pelayo, saluo si los hallaron en algún misal mozáraue". 
En realidad, Delicado, al privilegiar la modalidad andaluza del castellano en cuanto derivada directamente del habla de Castilla la Nueva, frente al gallego-portugués, u otras lenguas de la península, no está tan errado desde el punto de vista de la dialectología contemporánea. Porque "ni los Gallegos, ni Vizcaynos, ni Nauaros, ni Aragoneses, ni Portogeses, ni Catalanes, no conforman sus bárbaras lenguas con los Castellanos, como lo fazen los de Castilla la baxa que son de Toledo acá yuso". Esto es, todas las mencionadas son genéticamente otras lenguas, mientras que el andaluz, para decirlo en términos contemporáneos, es dialecto del castellano.

Más allá de su postura de bufón, que esconde la identidad de Delicado ante la carencia de un prestigio y de un estatus social, que son los que convierten un discurso en válido, convincente y aun legible, el olvidado clérido andaluz radicado en Italia alcanza a mostrar un juicio "político" independiente, una capacidad notable para la observación lingüística y ciertas cualidades de un teórico de literatura. Sin embargo, si bien en el prólogo al Primaleón la máscara de bufón del autor de $L a$ Lozana prevalece, la cronotopía distinta de esta nueva escritura - Venecia, y no Roma; después del Saco de Roma, no antes-, permite ver nuevos matices en su postura analítica ante el lenguaje literario.

\section{Bibliografía}

Alonso Gamo, José María (ed.), Viaje a España del magnífico señor ANDRÉS NAVAGERO (1524-1526), embajador de la República de Venecia ante el Emperador Carlos V, Valencia, Editorial Castalia, 1951.

Asensio, Eugenio, "Juan de Valdés contra Delicado. Fondo de una polémica", Homenaje a Dámaso Alonso, t. I, Madrid, Gredos, 1960, pp. 101-113. 
Avalle-Arce, Juan Bautista, "Amadís de Gaula": el primitivo y el de Montalvo, México, Fondo de Cultura Económica, 1990.

Cappelli, Adriano, Lexicon Abbreviaturam. Dizionario di abbreviature latine ed italiane usate nelle carte e codici specialmente del medio-evo..., 6 ed., Milán, Editore Ulrico Hoepli, 1993.

Chevalier, Maxime, "Juan de Valdés como crítico literario", $\mathrm{BHi}$, 102, 2, 2000, pp. 333-338.

Damiani, Bruno, y Louis ImPeriale, La Lozana Andaluza a través de los siglos, San Francisco-Londres-Bethesda, 1998.

EISENBERG, Daniel, "Inexactitudes y misterios bibliográficos: las primeras ediciones del Primaleón", Scriptura, 13, 1997, pp. 173178.

—, y Ma. Carmen Marían Pina, Bibliografía de los libros de caballerías castellanos, Zaragoza, Prensas Universitarias de Zaragoza, 2000.

Fucelli, Antonia, "Francisco Delicado come scrittore 'irregolare' ", QIA, 49-50, 1977, pp. 58-61.

Gallina, Anna Maria, "L'attività editoriale di due spagnoli a Venezia nella prima metà de '500' (Francisco Delicado e Domingo de Gaztelu)", Studi Hispanici, Pisa, 1962, pp. 69-91.

García Mercadal, J., “Andrés Navagero", prólogo a Viaje por España del magnífico micer Andrés Navagero, embajador de Venecia al emperador Carlos V, en Viajes de extranjeros por España y Portugal, ed. García Mercadal, Madrid, Aguilar, 1952.

Gayangos, Pascual de, Discurso Preliminar a Libros de caballerías I, BAE 40, Madrid, Atlas, 1963.

Los quatro libros de Amadís de Gaula nueuamente impressos \& hystoriados, edición de Francisco Delicado, Venezia, 1533.

Los tres libros del muy esforçado cauallero Primaleón et Polendos su hermano hijos del emperador Palmerín de Oliua, edición de Francisco Delicado, Venezia, 1534.

Lucía Megfas, José Manuel, Libros de caballerías castellanos en las bibliotecas públicas de París. Catálogo descriptivo, Pisa, Universita degli Studi di Pisa-Universidad de Alcalá, 1999.

Menéndez y Pelayo, Marcelino, Antología de los poetas líricos castellanos, X, Buenos Aires, Espasa-Calpe Argentina, 1952. 
NorTON, Frederick J., "The first edition of Primaleón, Salamanca 1512", BHS, 37, 1969, pp. 29-31.

Petrono, Giuseppe, et al., La letteratura degli italiani. Storia e Antologia, Roma, Palumbo, 1978.

Primaleón, Salamanca 1512, ed. de Ma. Carmen Marín Pina, Alcalá de Henares, Centro de Estudios Cervantinos, 1998.

Sarmati, Elisabetta, "Los libros de caballerías en el Diálogo de la lengua de Juan de Valdés", Siglo de Oro. Actas del IV Congreso Internacional de la AISO (Alcalá de Henares, 22-27 de julio de 1996), eds. M. C. García do Enterría y Alicia Cordón Mesa, Alcalá, Universidad, 1998, pp. 1491-1498.

Vian Herrero, Ana, El "Diálogo de Lactancio y un arcediano" de Alfonso de Valdés: obra de circunstancias y diálogo literario. Roma en el banquillo de Dios, Tolosa, Presses Universitaires du Mirail, 1994. 